\title{
Avaliação higiênico-sanitária de carne moída comercializada em açougues de Sarandi, PR, Brasil
}

\author{
Hygienic-sanitary evaluation of ground beef marketed \\ in butcheries in Sarandi, PR, Brazil
}

Recebido em: 14/03/2018 Aceito em: $11 / 06 / 2018$

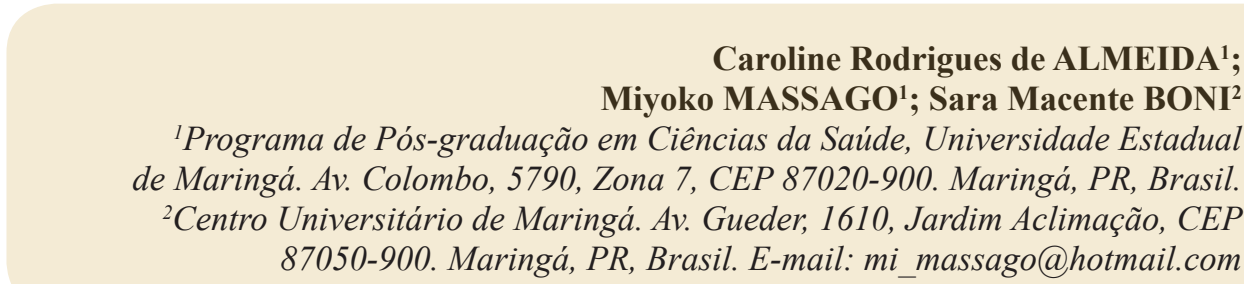

\section{ABSTRACT}

The beef consumption by Brazilian population has increased in recent years. However, the processing of this product can facilitate its contamination by microorganisms and trigger outbreaks of food infections. Based on the previous information, the present study aimed to evaluate the hygienic sanitary quality of ground beef marketed in 20 butcheries in the city of Sarandi, PR. Samples of 50 grams of the product were collected in each establishment. Then, the presence of total and thermotolerant coliforms was evaluated by Most Probable Number technique and Salmonella spp. by the growth in a specific medium. The presence of thermotolerant coliform was observed in all sample analyzed, but in none of them had growth of Salmonella spp. The presence of Escherichia coli in foods indicate a failure in the hygienic sanitary procedures, emphasizing the importance of implementing tools that promote improvement in the good hygiene practices, to reduce the contamination index of these products and to increase the quality of customer's life.

Keywords: microbiological analysis; bacteria; ground beef

\section{RESUMO:}

O consumo de carne bovina pela população brasileira tem aumentado nos últimos anos. No entanto, o processamento deste produto pode favorecer a sua contaminação por microrganismos e desencadear surtos de infecção alimentar. Baseado nestas informações, o objetivo do presente trabalho foi avaliar a qualidade higiênico-sanitária da carne moída comercializada em 20 açougues da cidade de Sarandi, PR. Foram coletadas amostras de 50 gramas do produto em cada estabelecimento. Em seguida foi verificada a presença de coliformes totais e termotolerantes pela Técnica do Número Mais Provável e de Salmonella spp. por crescimento em meio específico. Foi observada a presença de coliformes termotolerantes em todas as amostras analisadas; porém, em nenhuma delas houve o crescimento de Salmonella spp. A presença de Escherichia coli no alimento indica falha nos procedimentos higiênico-sanitários, ressaltando a importância de implementar medidas que promovam melhoria nas boas práticas de higiene, a fim de reduzir os índices de contaminação destes produtos e aumentar a qualidade de vida do consumidor.

Palavras-chave: análise microbiológica; bactérias; carne moída 


\section{INTRODUÇÃO}

O consumo de carne, com destaque à carne bovina, é praticado em diferentes partes do mundo por ser um alimento rico em proteínas (1). A carne moída é obtida por meio da trituração de massas musculares da carcaça bovina, seguida de resfriamento e congelamento (2). No entanto, a moagem favorece a contaminação e a proliferação de microrganismos patogênicos devido ao uso de equipamentos mal higienizados, à falta de limpeza de bancada e à má higiene dos manipuladores (3).

Um estudo realizado em cinco estabelecimentos comerciais de uma cidade de Minas Gerais mostrou que todos os equipamentos utilizados para a moagem da carne apresentavam contaminação microbiana acima do limite tolerado pela legislação e havia diversos microrganismos nas mãos dos manipuladores (4). Outra pesquisa revelou que os manipuladores são responsáveis por cerca de $26 \%$ da contaminação da carne (5). Contudo, apesar da sua importância, o comércio de produtos cárneos, em muitos casos, tem condições higiênico-sanitárias duvidosas, devido à falta de conhecimento dos vendedores e da população e deficiência no controle da qualidade por órgãos competentes (6), podendo levar à ingestão de carnes contendo microrganismos patogênicos.

A ingestão de carnes contaminadas pode ocasionar importantes patologias nos humanos e as suas consequências variam de acordo com o tipo e patogenicidade do microrganismo, idade do indivíduo, susceptibilidade ao patógeno, bem como da quantidade ingerida (7), ressaltando a importância da avaliação higiênico-sanitária destes produtos.

A avaliação higiênico-sanitária da carne pode ser realizada pela pesquisa de coliformes totais e termotolerantes e Salmonella spp. A detecção do primeiro grupo de bactérias é rotineiramente utilizada para avaliar a qualidade higiênico-sanitária dos alimentos em geral $(8,9)$.

Os coliformes são bacilos gram-negativos pertencentes à família das Enterobactérias, fermentadores de lactose com produção de gás a $45{ }^{\circ} \mathrm{C}$ (coliformes termotolerantes) ou a $37{ }^{\circ} \mathrm{C}$ (coliformes totais) (10). Os coliformes totais são frequentemente encontrados em diversos ambientes, como solo, vegetais, entre outros. No entanto, os termotolerantes são considerados enteropatógenos encontrados em fezes de animais de sangue quente (11).

A Salmonella spp. é considerada a vilã na infecção alimentar, pois apesar de ser encontrada em diversos ambientes, ocorre principalmente em alimentos de origem animal (12). Atualmente, a salmonelose é considerada um grave problema de saúde pública, no entanto a quantidade e a frequência deste patógeno na carne estão diretamente relacionadas com as condições higiênico-sanitárias durante a criação e o abate dos animais, bem como da manipulação da sua carne (13).

Para a assegurar a qualidade dos alimentos, o Ministério da Saúde, por meio da Agência Nacional de Vigilância Sanitária (Anvisa), aprovou o Regulamento Técnico sobre os padrões microbianos aceitáveis para alimentos (RDC n $\left.{ }^{\circ} 12 / 2001\right)$. Esta resolução estabelece que a Salmonella spp. deve estar ausente em 25 gramas de carne moída, todavia não há padrão para os coliformes nestes alimentos. Entretanto, o limite tolerado de coliformes em hambúrguer, produto industrializado da carne moída, é de 5 x $10^{3} \mathrm{UFC} / \mathrm{g}$ (14).

Apesar da existência de uma legislação que informa a quantidade máxima de microrganismos permitida nos diferentes alimentos, dados divulgados pelo Ministério da Saúde revelaram que entre os anos de 2007 e 2014 foram notificados 6632 surtos de Doenças Transmitidas por Alimentos (DTA), ocasionadas principalmente por Salmonella spp. (15). Nos Estados Unidos, anualmente, mais um milhão de indivíduos foram acometidos, ocasionando 23.000 hospitalizações e 450 mortes (16).

Devido à gravidade das doenças ocasionadas pelo consumo de produtos cárneos contaminados por bactérias, o presente trabalho teve o objetivo de avaliar a qualidade higiênico-sanitária da carne moída comercializada em açougues da cidade de Sarandi, norte do Paraná, por meio da pesquisa de Salmonella spp. e de coliformes.

\section{MATERIAL E MÉTODOS}

Obtenção das amostras. As amostras foram obtidas, no mês de maio de 2015, em 20 estabelecimentos comerciais de distribuição no varejo (açougues) localizados na cidade de Sarandi, norte do Paraná. Destes, 10 estavam situados na periferia da cidade e 10 no centro. De cada estabelecimento, foram obtidos 50 gramas de carne moída já exposta em gôndolas.

Após a obtenção, as amostras foram imediatamente armazenadas em caixas térmicas contendo gelo e encaminhadas para a análise no Laboratório de Microbiologia do Centro Universitário de Maringá (Unicesumar). No referido laboratório, as amostras foram homogeneizadas assepticamente e metade (25 
gramas) foi adicionada a $225 \mathrm{~mL}$ de uma solução de água peptonada esterilizada $(0,1 \%)$, sendo obtida uma diluição inicial 1:10. A partir desta, foram preparadas diluições decimais até 1:1000.

Testes microbiológicos. Para avaliar a presença de Coliformes Totais e Termotolerantes foi empregada a técnica do Número mais Provável (NMP), utilizando Caldo Lauril Sulfato de Triptose (LST), Caldo Lactosado Verde Brilhante (VB) e Caldo Escherichia coli (EC).

O teste presuntivo baseia-se na inoculação de 1 $\mathrm{mL}$ de cada diluição em três tubos contendo $9 \mathrm{~mL}$ de meio LST, adicionado de um tubo de Durham invertido e incubação à $37^{\circ} \mathrm{C}$ por 24 horas para a análise do crescimento microbiano e produção de gás (17). De cada amostra com resultado positivo no meio LST, foi transferida uma alçada para três tubos contendo meio VB para a quantificação de coliformes totais. Após a inoculação, os tubos foram incubados a $37{ }^{\circ} \mathrm{C}$ por 24 horas para a análise do crescimento microbiano e produção de gás.

Para a determinação do NMP dos coliformes termotolerantes a partir das amostras positivas no LST, foi inoculada uma alçada de cada amostra em três tubos contendo meio EC e incubados a $45{ }^{\circ} \mathrm{C}$ por 48 horas, para avaliar o crescimento microbiano e produção de gás.

A identificação de Salmonella spp. baseou-se nos testes bioquímicos para a sua identificação. Como teste presuntivo, 25 gramas de amostra pré-enriquecida em $225 \mathrm{~mL}$ de Água Peptonada Tamponada (APT), para a obtenção de uma diluição $1: 10$ e incubados $35{ }^{\circ} \mathrm{C}$ por 18 horas. Em seguida, foram transferidas alíquotas de $1 \mathrm{~mL} /$ tubo para os tubos contendo $9 \mathrm{~mL}$ do meio seletivo Caldo Selenito-Cistina e $0,1 \mathrm{~mL} /$ tubo em $9,9 \mathrm{~mL}$ do meio Caldo Rappaport-Vassiliadis e incubados $42{ }^{\circ} \mathrm{C}$ por 24 horas.

O isolamento deste grupo de bactérias foi realizado em Ágar Xilose Lisina Desoxicolato (XLD), Ágar Salmonella-Shiguella (SS) e Ágar Hektoen (HE). Para isso, de cada amostra positiva na etapa anterior, foram estriadas duas placas contendo XLD, SS e HE e incubadas a $35^{\circ} \mathrm{C}$ por 24 horas.

A identificação do gênero foi realizada por meio de testes bioquímicos de Citrato de Simmons, Vermelho de
Metila e Voges-Proskauer, Teste de Motilidade e Teste de Rugai \& Araújo modificado por Pessoa \& Silva.

\section{RESULTADOS E DISCUSSÃO}

Todas as 20 amostras analisadas no presente estudo apresentaram coliformes totais; $85 \%$ foram positivas para coliformes termotolerantes; e em nenhuma delas foi identificada Salmonella spp. A maioria das amostras sem coliformes termolerantes foi obtida no centro da cidade (Tabela 1).

Todas as amostras analisadas n estavam em conformidade com a RDC $\mathrm{n}^{\circ} 12$ de 2001, que preconiza a ausência de Salmonella spp. em 25 gramas de carne in natura. Este resultado corrobora com aqueles obtidos em outras cidades, como Uberlândia, MG e São Paulo, SP $(18,19)$ e, segundo a legislação vigente, a carne moída comercializada nestes estabelecimentos apresentam qualidade microbiológica satisfatória para o seu consumo. No entanto, é preciso ter cautela com relação à qualidade destes alimentos, uma vez que todos apresentaram coliformes totais, os quais são indicativos de má higienização do manipulador, equipamento e/ou ambiente.

O local de obtenção das amostras parece ser um fator importante na qualidade da carne comercializada na cidade de Sarandi, pois no presente trabalho as amostras adquiridas na periferia da cidade apresentaram maiores percentuais de contaminação com coliformes termotolerantes, assemelhando-se aos resultados obtidos por outros autores (20). Este resultado pode ser justificado, em parte, pelo fato de que na região central das cidades, as condições higiênico-sanitárias, em geral, são melhores devido à exigência do público consumidor, levando à menor taxa de contaminação dos alimentos por coliformes (21).

A grande quantidade de coliformes termotolerantes observada neste estudo, apesar de estar nos limites estabelecidos, pode ser reflexo da precariedade nos processos de manipulação e armazenamento do produto, bem como das condições higiênico-sanitárias inadequadas por parte dos manipuladores durante os processos de abate dos animais, transporte e armazenamento (3), permitindo assim a proliferação e a permanência de microrganismos. 
10.14450/2318-9312.v30.e2.a2018.pp110-114

Tabela 1. Local de coleta e quantidade (em NMP/g) de coliformes totais, coliformes termotolerantes e Salmonella spp. em carne moída comercializada nos açougues de Sarandi, PR.

\begin{tabular}{|c|c|c|c|c|}
\hline Amostra & Local & $\begin{array}{l}\text { Coliformes Totais } \\
\text { (NMP/g) }\end{array}$ & $\begin{array}{l}\text { Coliformes Termotolerantes } \\
\text { (NMP/g) }\end{array}$ & $\begin{array}{l}\text { Salmonella spp. } \\
\text { (NMP/g) }\end{array}$ \\
\hline 1 & Centro & $1,1 \times 10^{3}$ & $2,4 \times 10^{3}$ & ausente \\
\hline 2 & Centro & $1,1 \times 10^{3}$ & $2,4 \times 10^{3}$ & ausente \\
\hline 3 & Centro & $1,1 \times 10^{3}$ & $2,4 \times 10^{3}$ & ausente \\
\hline 4 & Centro & $1,1 \times 10^{3}$ & $2,4 \times 10^{3}$ & ausente \\
\hline 5 & Centro & $1,1 \times 10^{3}$ & $2,4 \times 10^{3}$ & ausente \\
\hline 6 & Centro & $1,1 \times 10^{3}$ & $2,4 \times 10^{3}$ & ausente \\
\hline 7 & Centro & $1,1 \times 10^{3}$ & $2,4 \times 10^{3}$ & ausente \\
\hline 8 & Centro & $1,1 \times 10^{3}$ & $2,4 \times 10^{3}$ & ausente \\
\hline 9 & Centro & $1,1 \times 10^{3}$ & ausente & ausente \\
\hline 10 & Centro & $1,1 \times 10^{3}$ & $2,4 \times 10^{3}$ & ausente \\
\hline 11 & Periferia & $1,1 \times 10^{3}$ & $2,4 \times 10^{3}$ & ausente \\
\hline 12 & Periferia & $1,1 \times 10^{3}$ & $2,4 \times 10^{3}$ & ausente \\
\hline 13 & Periferia & $1,1 \times 10^{3}$ & $2,4 \times 10^{3}$ & ausente \\
\hline 14 & Periferia & $1,1 \times 10^{3}$ & $2,4 \times 10^{3}$ & ausente \\
\hline 15 & Periferia & $1,1 \times 10^{3}$ & $2,4 \times 10^{3}$ & ausente \\
\hline 16 & Periferia & $1,1 \times 10^{3}$ & $2,4 \times 10^{3}$ & ausente \\
\hline 17 & Periferia & $1,1 \times 10^{3}$ & $2,4 \times 10^{3}$ & ausente \\
\hline 18 & Periferia & $1,1 \times 10^{3}$ & $2,4 \times 10^{3}$ & ausente \\
\hline 19 & Periferia & $1,1 \times 10^{3}$ & ausente & ausente \\
\hline 20 & Periferia & $1,1 \times 10^{3}$ & ausente & ausente \\
\hline
\end{tabular}

Apesar da Portaria de SVS/MS no 326 de 1997 estabelecer que os equipamentos e utensílios utilizados devam estar em bom estado de conservação e funcionamento e o estabelecimento livre de poeira, fumaça e umidade (22), os açougues onde foram obtidas as amostras analisadas no presente trabalho não apresentavam qualquer tipo de barreira contra poeiras e fumaças, proporcionando maior risco de contaminação microbiana dos produtos comercializados nestes locais.

Ainda, em todos os estabelecimentos visitados durante a coleta das amostras foi observada a presença de moscas. Este fato é preocupante, pois estes insetos são vetores potenciais da contaminação de alimento, portanto é de suma importância o seu controle nos locais onde são comercializados alimentos (23).

\section{CONCLUSÃO}

Pode-se concluir, apesar de todas as amostras de carne moída avaliadas no presente trabalho estarem de acordo com a legislação vigente, que o consumo deste produto deve ser realizado com cautela, pois a presença de coliformes indica falhas nos procedimentos higiênico-sanitários, Portanto, é de suma importância a implantação de programas que preconizem diminuir a contaminação deste produto e promovam a melhoria na saúde do consumidor. 


\section{REFERÊNCIAS}

1. Fiddes N. Meat: a natural symbol. $1^{\text {st }}$. London: Routledge. 1991.

2. BRASIL. Ministério da Agricultura, Pecuária e Abastecimento. Instrução normativa $\mathrm{n}^{\circ} 83$, de 21 de novembro de 2003. Aprova os Regulamentos Técnicos de identidade e qualidade de carne bovina em conserva (Corned Beff) e carne moída. Diário Oficial da União, 02 de novembro de 2003. Seção 1, p. 29.

3. Marchi PGF, Rossi Jr, OD, Cereser ND, Souza V, Rezende-Lago NCM, Faria AA. Avaliação microbiológica e físico-química da carne moída comercializada em supermercados e açougues de Jaboticabal-SP. Univar. 2012; 7: 81-87.

4. Oliveira MMM, Brugnera DF, Mendonça AT, Piccoli RH. Condições higiênico-sanitárias de máquinas de moer carne, mãos de manipuladores e qualidade microbiológica da carne moída. Ciênc. Agrotec. 2008; 32: 1893-1898. DOI: $10.1590 / \mathrm{S} 1413-7054200800060031$.

5. Alves VC, Cardoso Filho FC, Rios FPB, Lima CE, Keller KM, Muratori MCS. Coliformes e Salmonella spp. em carne moída comercializada em Teresina PI. Rev. Bras. Med. Vet. 2011; 33: 32-36.

6. Germano PML, Germano MIS. Higiene e Vigilância Sanitária de Alimentos. $3^{\text {rd }}$ ed. Barueri: Manole, 2008

7. Nascimento MVD, Guedes ATL, Silva HA, Santos VEP, Paz MCF. Avaliação da qualidade microbiológica da carne moída fresca comercializada no mercado central em campina grande-PB. Rev. Saúde Ciênc. 2014; 3(1): 5668.

8. Salvatori RU, Bessa MC, Cardoso MRI. Qualidade sanitária de embutidos coletados no mercado público central de Porto Alegre-RS. Ciênc. Rural. 2003; 33(4): 771-773. DOI: $10.1590 / \mathrm{S} 0103-84782003000400031$.

9. Leite AMO, Franco RM. Coliformes totais e Escherichia coli em coxas de frango comercializadas no Rio de Janeiro. Rev. Bras. Ciênc. Vet. 2006; 13(2):80-83.

10. Franco BDGM, Langraf M. Microbiologia dos Alimentos. São Paulo: Atheneu, 1996.

11. Souza CP. Segurança alimentar e doenças veiculadas por alimentos: utilização do grupo coliforme como um dos indicadores de qualidade de alimentos. Rev. APS. 2006; 9: 83-88.

12. Carvalho ACF, Cortez ALL. Salmonella spp. em carcaças, carne mecanicamente separada, linguiças e cortes comerciais de frango. Cienc. Rural. 2005; 35: 14651468. DOI: $10.1590 / \mathrm{S} 0103-84782005000600040$.

13. BRASIL. Ministério da Saúde. Higiene no preparo de alimentos evita contaminação por Salmonella spp. 2015. [Acesso em 09 mar 2018]. Disponível em: http://www. brasil.gov.br/saude/2015/01/higiene-no-preparo-de-alimentos-evita-contaminacao-por-salmonella/preparo-alimentos-cuidados/view.

14. BRASIL. Agência Nacional de Vigilância Sanitária. RDC $n^{\circ} 12$, de 02 de Janeiro de 2001. Aprova o Regulamento Técnico sobre os padrões Microbiológicos para Alimentos. Diário Oficial da União, $\mathrm{n}^{\circ} 12$ de 10 de janeiro de 2001. Seção 01. p. 45-53.

15. BRASIL. Ministério da Saúde. 2016. Surto de doenças transmitidas por alimentos. [Acesso em 09 mar 2018]. Disponível em: http://portalarquivos.saude.gov. br/images/pdf/2016/junho/08/Apresenta----o-Surtos-DTA-2016.pdf.

16. CDC. Center for Disease Control and Prevention, 2018. Reportus of Salmonella outbreak investigation from 2018. [Acesso em 09 mar 2018]. Disponível em: https:// www.cdc.gov/salmonella/outbreaks-2018.html.

17. Rosina A, Monego F. Avaliação microbiológica da carne bovina moída nas redes de supermercados de Canoinhas/SC. RESMA. 2013; 2: 55-64. DOI: 10.24302/sma. v2i2.468.

18. Ferreira IM. Riscos relacionados à contaminação microbiana de carne moída bovina. [Dissertação]. Urberlândia. Faculdade de Medicina Veterinária, Universidade Federal de Uberlândia. 2008.

19. Costa CAR. Avaliação da exposição do consumidor à Listeria monocytogenes, Salmonella spp., Campylobacter spp. e Escherichia coli produtora de toxina de Shiga em produtos cárneos refrigerados comercializados no município de São Paulo. [Tese]. São Paulo. Faculdade de Ciências Farmacêuticas, Universidade de São Paulo. 2010 .

20. Lima ROR. Qualidade microbiológica de carne moída in natura comercializada em Boa Vista-Roraima. [Monografia]. Boa Vista. Curso de Ciências Biológicas, Faculdade Cathedral. 2009.

21. Yamoto DC, Marlet EF, Silva FR. Caracterização das condições higiênico-sanitárias dos restaurantes fast food de dois shopping centers em diferentes regiões do município de São Paulo. Hig. Alim. 2004, 18:14-20

22. BRASIL. Agência Nacional de Vigilância Sanitária. Portaria $n^{\circ} 326$ de 30 de julho de 1997. Aprova o Regulamento Técnico sobre as condições higiênico-sanitárias e de boas práticas de fabricação para estabelecimentos produtores/industrializadores de alimentos. Diário Oficial da União, no 12 de 01 de agosto de 1997. Seção 01.

23. Lucca A, Torres EAFS. Condições de higiene de "cachorro- quente" comercializado em vias públicas. Rev. Saúde Públ. 2002; 3: 350-352. DOI: 10.1590/S003489102002000300015 . 